\title{
Dextrocardia and Situs Viscerum Inversus: the Challenge of Operating on the Mirror Image Anatomy
}

Marco Gennari ${ }^{1}$ and Marco Agrifoglio ${ }^{1}$

${ }^{1}$ Centro Cardiologico Monzino Istituto di Ricovero e Cura a Carattere Scientifico

April 28, 2020

\section{Abstract}

Situs viscerum inversus always poses clinical and diagnostic challenge. We report the case of an unexpected and late discover of dextrocardia requiring aortic valve replacement.

\section{Hosted file}

Manuscript.doc available at https://authorea.com/users/314418/articles/444795-dextrocardia-andsitus-viscerum-inversus-the-challenge-of-operating-on-the-mirror-image-anatomy

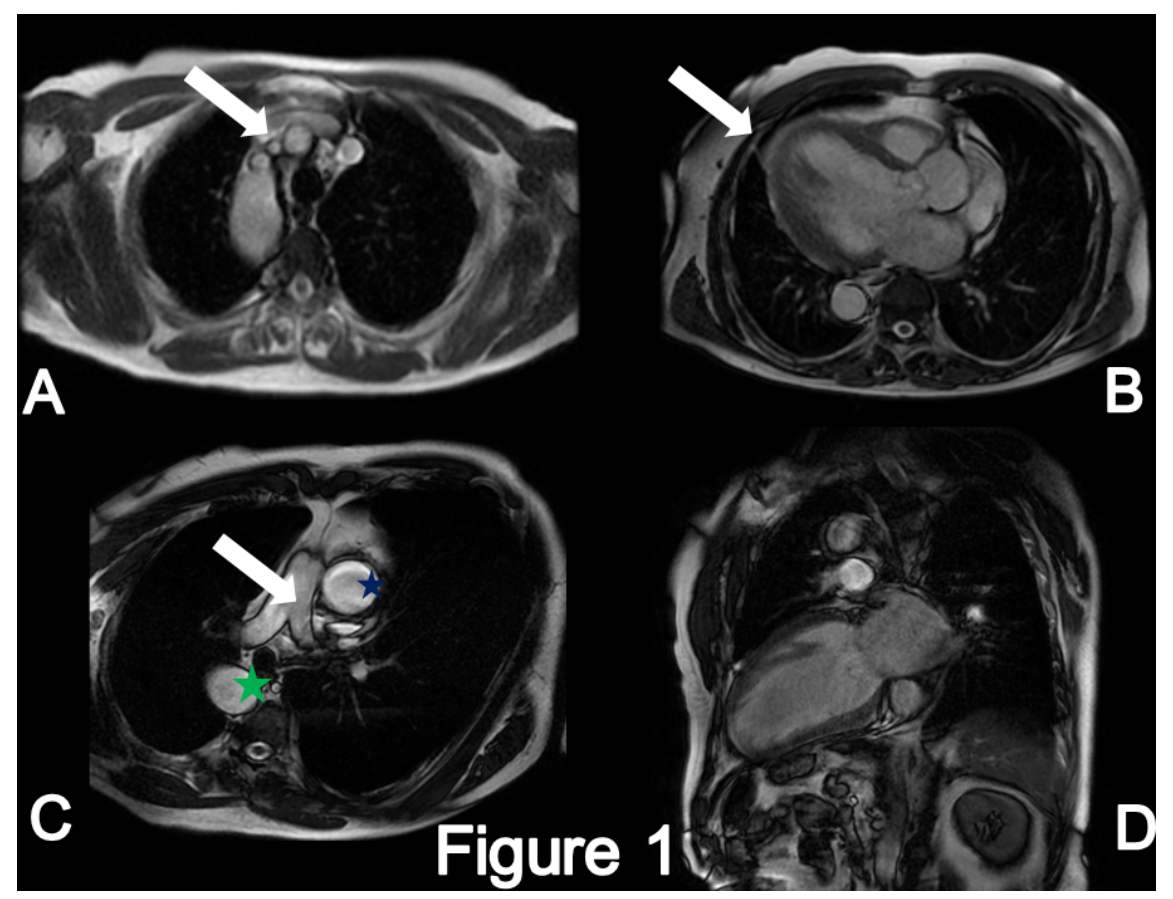



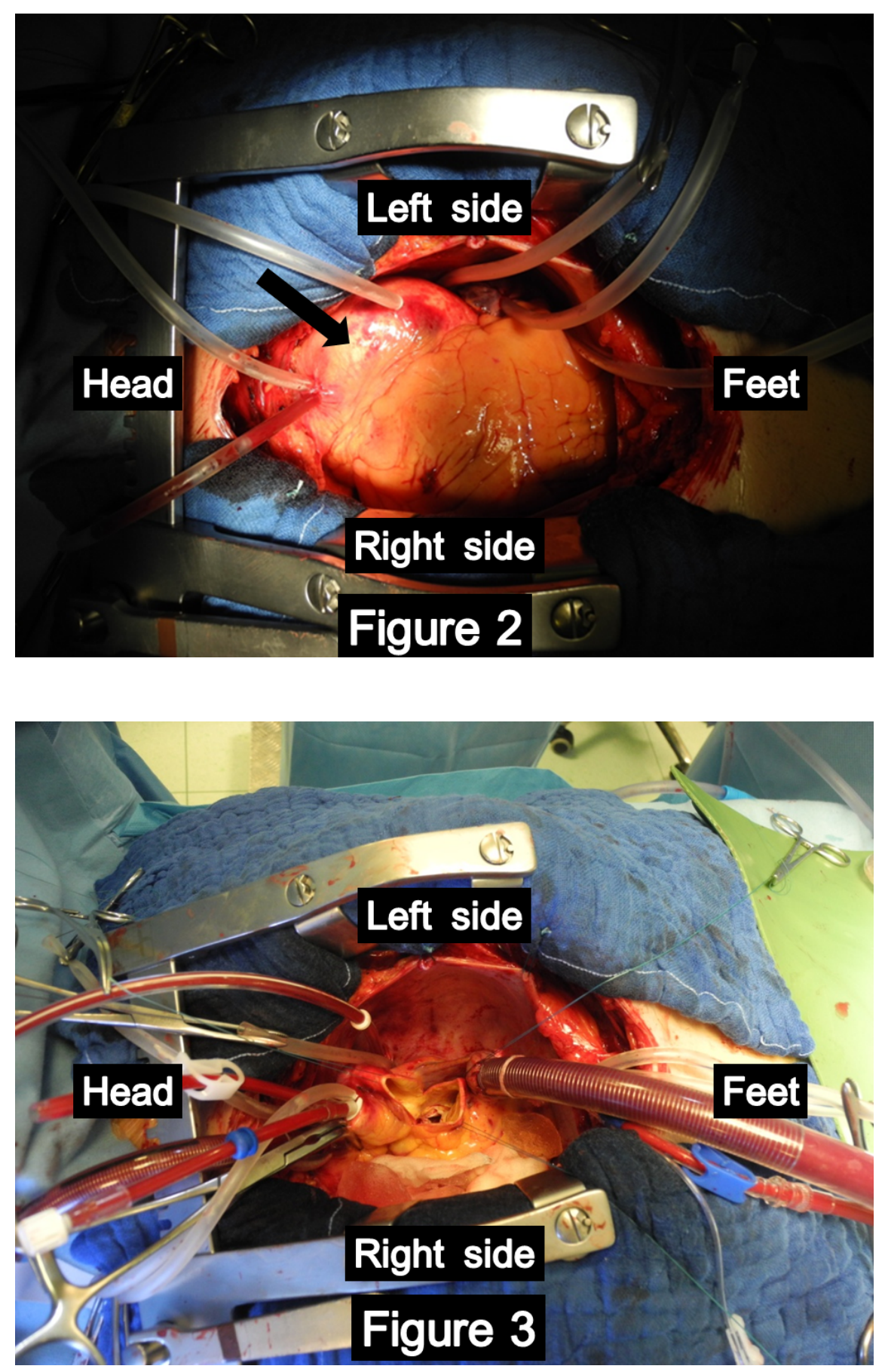